\title{
Hybrid macrocycle formation and spiro annulation on cis-syn-cis-tricyclo[6.3.0.0 2,6] undeca-3,11-dione and its congeners via ring-closing metathesis
}

\author{
Sambasivarao Kotha*, Ajay Kumar Chinnam and Rashid Ali
}

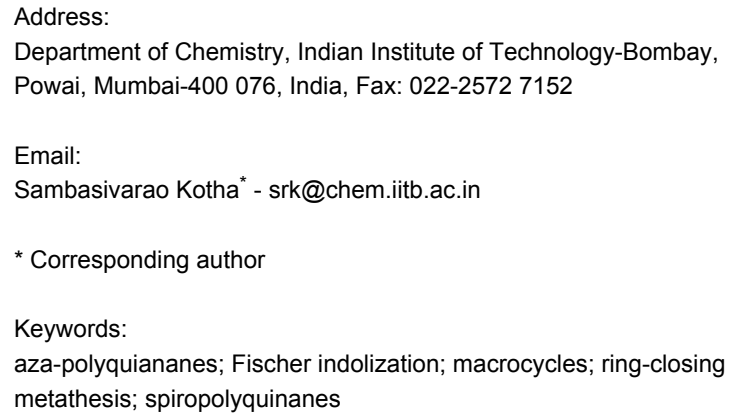

Beilstein J. Org. Chem. 2015, 11, 1123-1128. doi:10.3762/bjoc. 11.126

Received: 23 February 2015

Accepted: 23 June 2015

Published: 06 July 2015

This article is part of the Thematic Series "Progress in metathesis chemistry II".

Guest Editor: K. Grela

(C) 2015 Kotha et al; licensee Beilstein-Institut. License and terms: see end of document.

\begin{abstract}
We have developed a simple methodology to transform cis-syn-cis-triquinane derivative $\mathbf{2}$ into the diindole based macrocycle $\mathbf{6}$ involving Fischer indolization and ring-closing metathesis (RCM). Various spiro-polyquinane derivatives have been assembled via RCM as a key step.
\end{abstract}

\section{Introduction}

Design and synthesis of polyquinanes is an active area of research during the last three decades [1-10]. Various theoretically interesting as well as biologically active molecules such as dodecahedrane, [5.5.5.5] fenestrane and retigeranic acid A contain the quinane framework in their structures (Figure 1). A variety of quinane-based natural products isolated from terrestrial, microbial and marine sources have stimulated the growth of polyquinane chemistry. In this context, there is a continuous demand for the development of new methodologies to assemble cyclopentanoids (or quinanes) [11-21]. Several approaches are available for the synthesis of carbocyclic quinanes, however, only a limited number of methods is available for oxa- [22-25] and aza-polyquinanes [26-28]. The indole unit is present in a variety of plant alkaloids (e.g., reserpine, strychnine, physostigmine) and several important drugs contain indole as a key component [29-32]. Therefore, we are interested in designing new strategies to hybrid molecules containing both quinane and indole ring systems. On several occasions, the spirocyclic moiety seems to be a recurring motif in bioactive molecules. Consequently, assembling architecturally complex spirocycles is of great relevance to the diversity-oriented synthesis of biologically active spirocycles. In this context, new synthetic methods to generate multiple spirocenters in a simple manner remain a challenging task. Although, a variety of strategies have been investigated, a limited number of general methods are available [33-46] for the generation of multiple spirocenters in a 


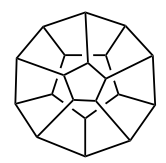

dodecahedrane

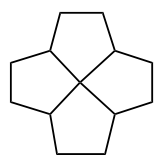

[5.5.5.5]fenestrane

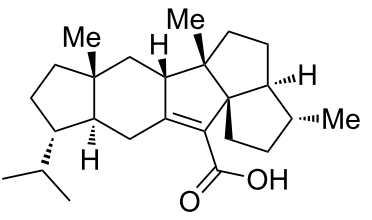

retigeranic acid $A$

Figure 1: Natural and non-natural products containing quinane systems.

single step [43]. To expand the chemical space of azapolyquinanes we conceived a new strategy based on Fischer indolization and ring-closing metathesis as the key steps.

To develop a simple synthetic methodology to aza-polycycles and spiropolycycles from readily available starting materials [47-52], bicyclic, tricyclic and pentacyclic diones (1-3) were identified as useful building blocks (Figure 2). The selection of these diones is based on their easy accessibility and also the symmetry involved with them. For example, with diones $\mathbf{1}$ and 2 one can apply a two-directional synthesis [53] to increase the brevity [54] of the overall synthesis. Earlier, we have shown that Weiss-Cook dione 1 [49-51] is a useful substrate for double Fischer indolization with a low melting mixture of L-(+)-tartaric acid and $N, N^{\prime}$-dimethylurea (L-(+)-TA:DMU) [55] at $70{ }^{\circ} \mathrm{C}$ to generate an unusual $C_{\mathrm{s}}$-symmetric diindole derivative along with the known $C_{2}$-symmetric diindole [56]. Also, based on Fischer indolization and ring-closing metathesis (RCM), we have developed a new strategy to indole-based propellane derivatives [57].
Here, the tricyclic dione 2 required was prepared starting with the Cookson's dione 4 in two steps involving flash vacuum pyrolysis (FVP) and hydrogenation steps (Scheme 1). A variety of synthetic transformations involving tricyclic diones $\mathbf{5}$ and $\mathbf{2}$ were reported in the literature [47].

To expand the utility of building block $\mathbf{2}$ in organic synthesis, we conceived a simple retrosynthetic approach to macrocylic aza-polyquinane 6 and spiro-polyquinane derivative 7 (Figure 3). The key steps involved here are: double Fischer indolization and RCM. To install the alkane chain connecting the two nitrogen atoms, we plan to use alkylation with allylbromide followed by RCM and hydrogenation protocols. It is known that a mono-indole derivative was obtained via Fischer indolization starting with dione 2 and two equivalents of phenylhydrazine hydrochloride, but the diindole derivative $\mathbf{8}$ [58] was not obtained under these conditions. Our experience with Fischer indolization of $\mathbf{1}$ using the low melting mixture protocol gave unusual results as compared with conventional Fischer indolization conditions. Therefore, the reactivity of $\mathbf{2}$

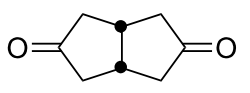

1

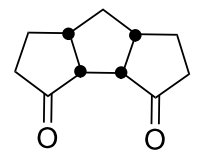

2

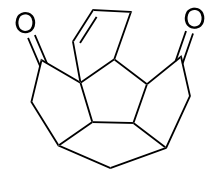

$3 a$

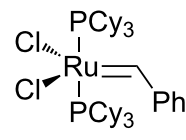

(G-I)

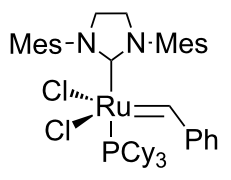

(G-II)

Figure 2: Quinane building blocks (1-3) and metathetic catalyst used in our strategy.

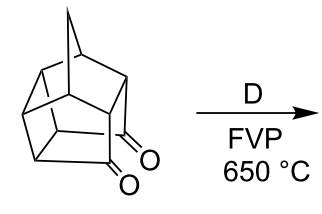

4

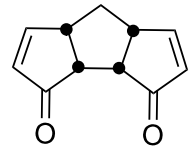

5
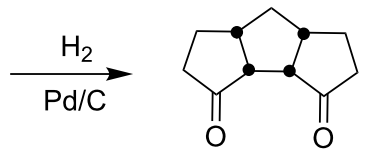

2 


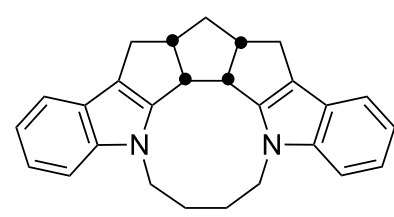

6

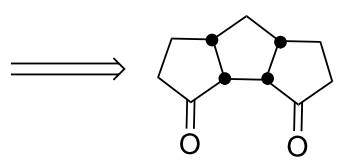

2

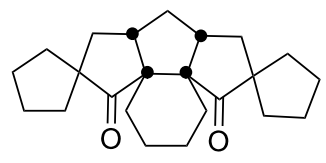

7

Figure 3: Retrosynthetic approach to aza-polyquinane 6 and spiro-polyquinane 7.

under conditions of the low melting mixture is worthy of systematic investigation. Here, we are pleased to report our successful results in generating the diindole derivative $\mathbf{8}$ by utilizing a low melting mixture of L-(+)-TA:DMU and its subsequent utility in assembling the macrocyclic system 6 via RCM. During this venture, we also found that the tricyclic dione $\mathbf{2}$ is a useful substrate for the synthesis of spiropolyquinane derivative 7 via a six fold allylation followed by a three-fold RCM and a hydrogenation sequence.

\section{Results and Discussion}

To realize the strategy shown in Figure 3, the tricyclic dione 2 was subjected to a two-fold Fischer indolization in the presence of two equivalents of phenylhydrazine hydrochloride with the aid of a low melting mixture of L-(+)-TA:DMU to generate the diindole derivative 8 (62\%, Scheme 2$)$. The structure of the diindole $\mathbf{8}$ has been established on the basis of ${ }^{1} \mathrm{H}$ NMR and ${ }^{13} \mathrm{C}$ NMR spectral data. The presence of
12 signals in the ${ }^{13} \mathrm{C}$ NMR spectrum clearly indicated that the $C_{\mathrm{s}}$-symmetry is present in molecule $\mathbf{8}$. Later, the diindole derivative was treated with methyl iodide in the presence of $\mathrm{NaH} / \mathrm{DMF}$ at room temperature to deliver the dimethyl derivative 9. Again, the $C_{\mathrm{S}}$-symmetry present in $\mathbf{9}$ is evidenced by the appearance of 13 signals in the ${ }^{13} \mathrm{C}$ NMR spectrum. Alternatively, the diindole derivative $\mathbf{9}$ has been generated in a single step by reacting the dione 2 with $N$-methyl- $N$-phenylhydrazine under conditions using the described low melting mixture.

Next, the $N$-allylation of the diindole derivative 8 with allyl bromide in the presence of NaH/DMF gave diallyl derivative 10, which was subjected to the RCM sequence in the presence of Grubbs' $2^{\text {nd }}$ generation catalyst to produce the cyclized compound $11(84 \%)$. Subsequently, the macrocyclic diindole derivative 11 was hydrogenated in the presence of $\mathrm{H}_{2} / \mathrm{Pd} / \mathrm{C}$ to afford the saturated compound 6 (Scheme 3).

(iii)

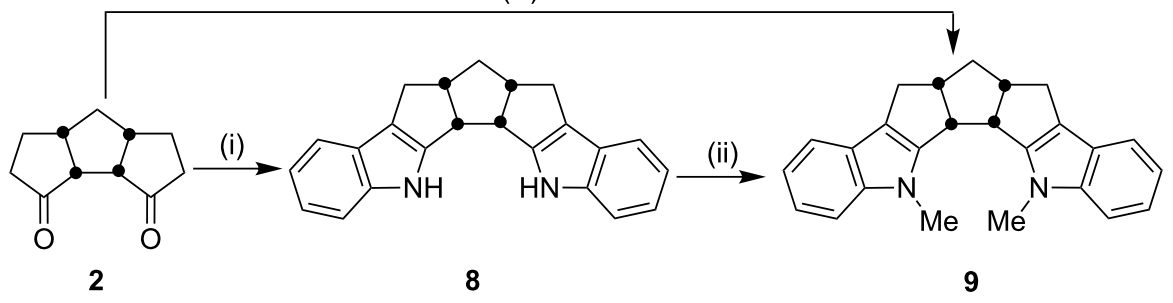

Scheme 2: Synthesis of the diindole derivative 9 Reagents and conditions: (i) TA:DMU, $\mathrm{PhNHNH}_{3} \mathrm{Cl}, 70{ }^{\circ} \mathrm{C}, 6 \mathrm{~h}, 62 \%$; (ii) $\mathrm{NaH}, \mathrm{Mel}, \mathrm{DMF}, \mathrm{rt}, 24 \mathrm{~h}$, 87\%; (iii) TA:DMU, $70{ }^{\circ} \mathrm{C}, \mathrm{PhNMeNH}_{2}, 6 \mathrm{~h}, 76 \%$.

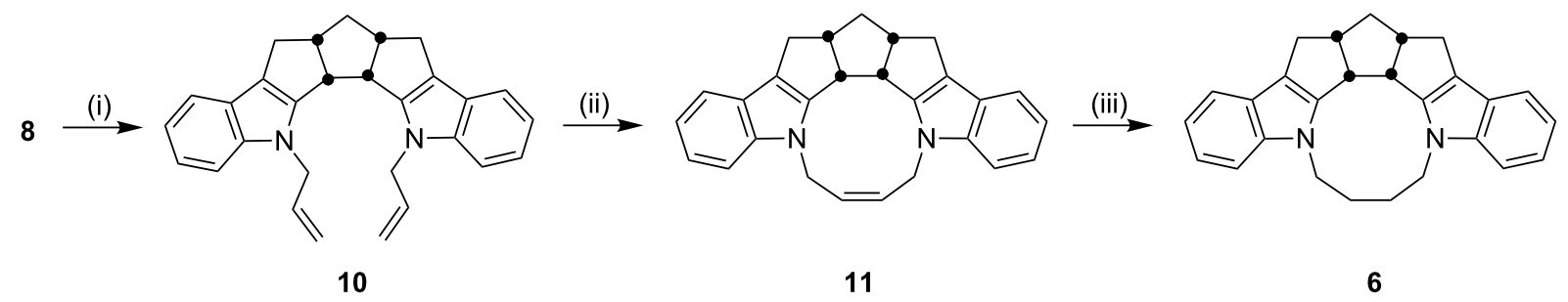

Scheme 3: Synthesis of the macrocyclic aza-polyquinane derivative 6. Reagents and conditions: (i) NaH, allyl bromide, DMF, rt, $24 \mathrm{~h}, 65 \%$; (ii) G-II, $\mathrm{CH}_{2} \mathrm{Cl}_{2}$, rt, $12 \mathrm{~h}, 84 \%$; (iii) $\mathrm{Pd} / \mathrm{C}, \mathrm{H}_{2}$, EtOAc, rt, $18 \mathrm{~h}, 95 \%$. 
To assemble the intricate spiro-polyquinane 7 via RCM as a key step [59-62], we started with the triquinane derivative 2 . To this end, the cis-syn-cis-triquinane dione $\mathbf{2}$ was treated with an excess amount of allyl bromide in the presence of $\mathrm{NaH}$ to generate the hexaallyl derivative $\mathbf{1 2}$ in 59\% yield. Later, it was subjected to RCM with Grubbs' $1^{\text {st }}$ generation catalyst to deliver the three-fold RCM product $\mathbf{1 3}$ in $80 \%$ yield. Furthermore, treatment of the hexacyclic dione 13 with $\mathrm{Pd} / \mathrm{C}$ in EtOAc under hydrogen atmosphere (1 atm) gave the saturated spiropolyquinane 7 in $90 \%$ yield (Scheme 4 ). Very few examples are known in the literature where multiple RCM was performed in a single operation to generate the molecules of medium molecular weight [63]. The present example involving the generation of triple spirocyclic compound 7 is unique and demonstrates the power and scope of the RCM approach. It is worth mentioning that previous attempts to functionalize 2 were unsuccessful [47].

To generalize the spiroannulation sequence, allylation of pentacyclic diones 3a-c [48] gave the tetraallyl diones $\mathbf{1 4 a - c}$ in respectable yields. Next, treatment of these allylated derivatives 14a-c with G-I catalyst gave the double RCM products 15a, 15b and 15c in $92 \%, 92 \%$ and $91 \%$ yields, respectively (Scheme 5 and Table 1). Later, these double RCM products were subjected to the hydrogenation protocol in the presence of $\mathrm{H}_{2} / \mathrm{Pd} / \mathrm{C}$ to deliver the saturated bis-spiro-polyquinane derivatives 16a, 16b and 16a in an excellent yield (Table 1). Similarly, the dione 3a in the presence of an excess amount of $\mathrm{NaH}$ and allyl bromide gave the pentaallyl dione 14d in $67 \%$ yield (Table 1). Next, the pentaallyl derivative 14d was treated with G-I catalyst to produce the bis-spiro-polyquinane 15d. ${ }^{1} \mathrm{H}$ NMR and ${ }^{13} \mathrm{C}$ NMR spectral data clearly indicated the presence of intact allyl residue along with the unsaturated double bonds. The bis-spiro-polyquinane $\mathbf{1 5 d}$ was then subjected to hydrogenation sequence to deliver the saturated bis-spiro-polyquinane 16d in good yield (Table 1).

\section{Conclusion}

In summary, we have developed a protocol for the synthesis of a diindole-based hybrid macrocycle through Fischer indoliza-

\footnotetext{
Scheme 4: Synthesis of the spiro-polyquinane 7. Reagents and conditions: (i) NaH, allyl bromide, THF, rt, 24 h, $59 \%$; (ii) G-I, $\mathrm{CH}_{2} \mathrm{Cl}_{2}$, rt, $15 \mathrm{~h}, 80 \%$; (iii) $\mathrm{Pd} / \mathrm{C}, \mathrm{H}_{2}$, EtOAc, rt, $24 \mathrm{~h}, 90 \%$.
}

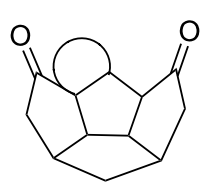

$3 a-c$

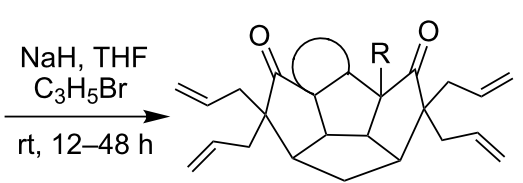

$14 a-d(60-74 \%)$

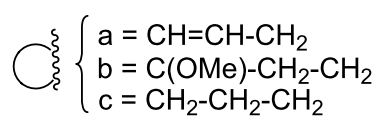

$\mathrm{d}=\mathrm{R}=\mathrm{CH}_{2} \mathrm{CH}=\mathrm{CH}_{2}$ (or) $\mathrm{H}$ $\mathrm{R}^{1}=\mathrm{CH}_{2} \mathrm{CH}_{2} \mathrm{CH}_{3}$ (or) $\mathrm{H}$
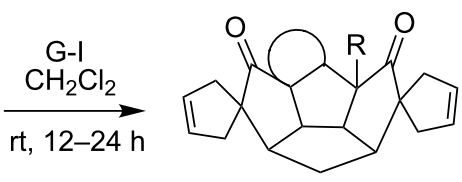

$15 a-d(85-92 \%)$

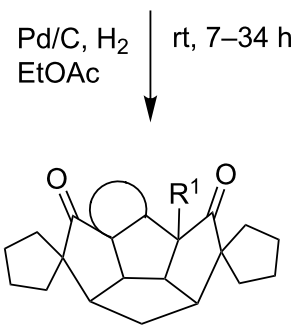

$16 a-d(98-99 \%)$ 


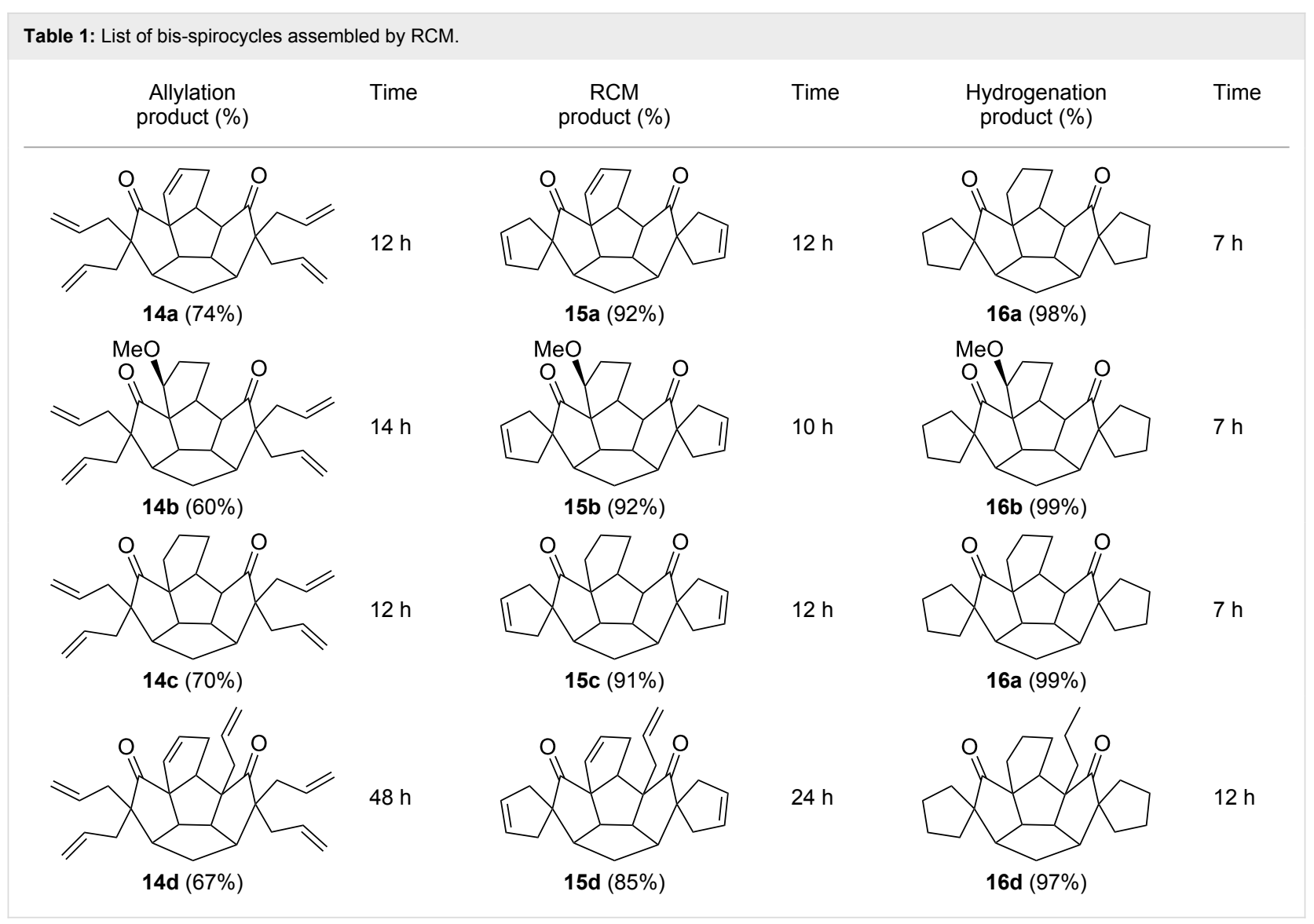

tion of the triquinane 2 followed by bis- $N$-allylation and RCM The allylation-RCM sequence has also been extended to construct structurally intricate spiro-polyquinanes.

\section{Supporting Information}

\section{Supporting Information File 1}

Experimental and analytical data.

[http://www.beilstein-journals.org/bjoc/content/ supplementary/1860-5397-11-126-S1.pdf]

\section{Supporting Information File 2}

\section{NMR spectra.}

[http://www.beilstein-journals.org/bjoc/content/ supplementary/1860-5397-11-126-S2.pdf]

\section{Acknowledgements}

AKC and RA acknowledge the University Grant Commission, New Delhi for the award of research fellowships. SK thanks the DST for the award of a J. C. Bose fellowship. We also thank the CSIR (New Delhi) and the Department of Science and Technology (DST), New Delhi for the financial support. We thank Prof. G. Mehta for valuable suggestions.

\section{References}

1. Greenberg, A.; Liebman, J. F. Strained Organic Molecules; Academic Press: New York, 1978.

2. Olah, G. A. Cage Hydrocarbons; John-Wiley: New York, 1990.

3. Vögtle, F. Fascinating Molecules in Organic Chemistry; Wiley : Chichester, 1992

4. Ōsawa, E.; Yonemitsu, O. Carbocyclic Cage Compounds: Chemistry and Applications; VCH: New York, 1992.

5. Hopf, H. Classics in Hydrocarbon Chemistry; Wiley-VCH: Weinheim, 2000.

6. Mehta, G.; Srikrishna, A. Chem. Rev. 1997, 97, 671. doi:10.1021/cr9403650

7. Wender, P. A.; Dore, T. M.; deLong, M. A. Tetrahedron Lett. 1996, 37, 7687. doi:10.1016/0040-4039(96)01740-6

8. Tzvetkov, N. T.; Neumann, B.; Stammler, H.-G.; Mattay, J. Eur. J. Org. Chem. 2006, 351. doi:10.1002/ejoc.200500546

9. Camps, P.; Fernández, J. A.; Vázquez, S. ARKIVOC 2010, No. iv, 74. doi:10.3998/ark.5550190.0011.407

10. Paquette, L. A.; Doherty, A. M. Polyquinane Chemistry, Synthesis and Reactions; Springer-Verlag: New York, 1987.

11. Ramaiah, M. Synthesis 1984, 529. doi:10.1055/s-1984-30893

12. Singh, V.; Thomas, B. Tetrahedron 1998, 54, 3647. doi:10.1016/S0040-4020(97)10426-4

13. Toyota, M.; Nishikawa, Y.; Motoki, K.; Yoshida, N.; Fukumoto, K. Tetrahedron 1993, 49, 11189. doi:10.1016/S0040-4020(01)81806-8

14. Liao, C.-C. Pure Appl. Chem. 2005, 77, 1221. doi:10.1351/pac200577071221

15. Srikrishna, A.; Dethe, D. H. Indian J. Chem. 2011, 50B, 1092. 
16. Tolstikov, G. A.; Ismailov, S. A.; Gimalova, F. A.; Ivanova, N. A.; Miftakhov, M. S. Russ. Chem. Bull. 2013, 62, 226. doi:10.1007/s11172-013-0035-z

17. Heasley, B. Curr. Org. Chem. 2014, 18, 641. doi:10.2174/13852728113176660150

18. Chaplin, J. H.; Jackson, K.; White, J. M.; Flynn, B. L. J. Org. Chem. 2014, 79, 3659. doi:10.1021/Jo500040b

19. Álvarez-Fernández, A.; Suárez-Rodriguez, T.; Suárez-Sobrino, Á. L. J. Org. Chem. 2014, 79, 6419. doi:10.1021/Jo500378z

20. Tymann, D.; Klüppel, A.; Hiller, W.; Hiersemann, M. Org. Lett. 2014, 16, 4062. doi:10.1021/OI501204m

21. Nagaraju, C.; Prasad, K. R. Angew. Chem., Int. Ed. 2014, 53, 10997. doi:10.1002/anie.201407680

22. Hext, N. M.; Hansen, J.; Blake, A. J.; Hibbs, D. E.; Hursthouse, M. B.; Shishkin, O. V.; Mascal, M. J. Org. Chem. 1998, 63, 6016. doi:10.1021/jo980788s

23. Jevric, M.; Zheng, T.; Meher, N. K.; Fettinger, J. C.; Mascal, M. Angew. Chem., Int. Ed. 2011, 50, 717. doi:10.1002/anie.201006470

24. Li, Y.; Meng, Y.; Meng, X.; Li, Z. Tetrahedron 2011, 67, 4002. doi:10.1016/j.tet.2011.04.031

25. Ramakrishna, K.; Kaliappan, K. P. Synlett 2011, 2580. doi:10.1055/s-0030-1289518

26. McClure, C. K.; Kiessling, A. J.; Link, J. S. Org. Lett. 2003, 5, 3811. doi:10.1021/ol035202p

27. Singh, V.; Sahu, B. C.; Mobin, S. M. Synlett 2008, 1222. doi:10.1055/s-2008-1072588

28. Bandaru, A.; Kaliappan, K. P. Synlett 2012, 1473. doi:10.1055/s-0031-1290375

29. Wilson, L. J.; Yang, C.; Murray, W. V. Tetrahedron Lett. 2007, 48, 7399. doi:10.1016/j.tetlet.2007.08.006

30. Simonov, A. Y.; Bykov, E. E.; Lakatosh, S. A.; Luzikov, Y. N.; Korolev, A. M.; Reznikova, M. I.; Perobrazhenskaya, M. N. Tetrahedron 2014, 70, 625. doi:10.1016/j.tet.2013.12.004

31. Torney, P.; Shirsat, R.; Tilve, S. Synlett 2014, 25, 2121. doi:10.1055/s-0034-1378536

32. Davis, F.; Higson, S. Macrocycles: Construction, Chemsitry and Nanotechnology Applications; John Wiley \& Sons: Chichester, 2011.

33. Kotha, S.; Manivannan, E.; Ganesh, T.; Sreenivasachary, N.; Deb, A. Synlett 1999, 1618. doi:10.1055/s-1999-2896

34. Kotha, S.; Sreenivasachary, N. Indian J. Chem. 2001, 40B, 763.

35. Wybrow, R. A. J.; Edwards, A. S.; Stenvenson, N. G.; Adams, H.; Johnstone, C.; Harrity, J. P. A. Tetrahedron 2004, 60, 8869. doi:10.1016/j.tet.2004.07.025

36. Justus, J.; Beck, T.; Noltemeyer, M.; Fitjer, L. Tetrahedron 2009, 65, 5192. doi:10.1016/j.tet.2009.05.005

37. Meyer-Wilmes, I.; Gerke, R.; Fitjer, L. Tetrahedron 2009, 65, 1689. doi:10.1016/j.tet.2008.12.025

38. Widjaja, T.; Fitjer, L.; Meindl, K.; Herbst-Irmer, R. Tetrahedron 2008, 64, 4304. doi:10.1016/j.tet.2008.02.073

39. Kotha, S.; Srinivas, V.; Krishna, N. G. Heterocycles 2012, 86, 1555. doi:10.3987/COM-12-S(N)89

40. Kotha, S.; Deb, A. C.; Kumar, R. V. Bioorg. Med. Chem. Lett. 2005, 15, 1039. doi:10.1016/j.bmcl.2004.12.034

41. Kotha, S.; Chavan, A. S.; Mobin, S. M. J. Org. Chem. 2012, 77, 482. doi:10.1021/jo2020714

42. Kotha, S.; Dipak, M. K. Tetrahedron 2012, 68, 397. doi:10.1016/j.tet.2011.10.018

43. D'yakonov, V. A.; Trapeznikova, O. A.; de Meijere, A.; Dzhemilev, U. M. Chem. Rev. 2014, 114, 5775. doi:10.1021/cr400291c
44. Kotha, S.; Mandal, K. Tetrahedron Lett. 2004, 45, 1391. doi:10.1016/j.tetlet.2003.12.075

45. Kotha, S.; Mandal, K.; Deb, A. C.; Banerjee, S. Tetrahedron Lett. 2004, 45, 9603. doi:10.1016/j.tetlet.2004.11.012

46. Kotha, S.; Mandal, K. Chem. - Asian J. 2009, 4, 354. doi:10.1002/asia.200800244

47. Mehta, G.; Srikrishna, A.; Reddy, A. V.; Nair, M. S. Tetrahedron 1981, 37, 4543. doi:10.1016/0040-4020(81)80021-X

48. Mehta, G.; Kotha, S. R. J. Org. Chem. 1985, 50, 5537. doi:10.1021/jo00350a021

49. Bertz, S. H.; Cook, J. M.; Gawish, A.; Weiss, U. Org. Synth. 1986, 64, 27. doi:10.15227/orgsyn.064.0027

50. Gupta, A. K.; Fu, X.; Snydert, J. P.; Cook, J. M. Tetrahedron 1991, 47, 3665. doi:10.1016/S0040-4020(01)80896-6

51. Fu, X.; Cook, J. M. Aldrichimica Acta 1992, 25, 43.

52. Kotha, S.; Sivakumar, R.; Damodharan, L.; Pattabhi, V. Tetrahedron Lett. 2002, 43, 4523. doi:10.1016/S0040-4039(02)00815-8

53. Magnuson, S. R. Tetrahedron 1995, 51, 2167. doi:10.1016/0040-4020(94)01070-G

54. Hudlicky, T.; Reed, J. W. The Way of Synthesis; Wiley-VCH: Weinheim, 2007; p 89.

55. Gore, S.; Baskaran, S.; König, B. Org. Lett. 2012, 14, 4568. doi:10.1021/ol302034r

56. Kotha, S.; Chinnam, A. K. Synthesis 2013, 46, 301. doi:10.1055/s-0033-1340341

57. Kotha, S.; Chinnam, A. K.; Tiwari, A. Beilstein J. Org. Chem. 2013, 9 , 2709. doi:10.3762/bjoc.9.307

58. Mehta, G.; Prabhakar, C. Indian J. Chem. 1995, 34B, 267.

59. Kotha, S.; Ali, R.; Tiwari, A. Synlett 2013, 24, 1921. doi:10.1055/s-0033-1339489

60. Kotha, S.; Ali, R. Heterocycles 2014, 88, 789. doi:10.3987/COM-13-S(S)48

61. Kotha, S.; Ali, R.; Chinnam, A. K. Tetrahedron Lett. 2014, 55, 4492. doi:10.1016/j.tetlet.2014.06.049

62. Kotha, S.; Ali, R.; Tiwari, A. Synthesis 2014, 46, 2471. doi:10.1055/s-0034-1378280

63. Wallace, D. J. Tetrahedron Lett. 2003, 44, 2145. doi:10.1016/S0040-4039(03)00161-8

\section{License and Terms}

This is an Open Access article under the terms of the Creative Commons Attribution License (http://creativecommons.org/licenses/by/2.0), which permits unrestricted use, distribution, and reproduction in any medium, provided the original work is properly cited.

The license is subject to the Beilstein Journal of Organic Chemistry terms and conditions: (http://www.beilstein-journals.org/bjoc)

The definitive version of this article is the electronic one which can be found at:

$\underline{\text { doi:10.3762/bjoc. } 11.126}$ 